\title{
Pharmacokinetic Study of SKL-18287, a Novel Long-Acting Glucagon-Like Peptide-1 Receptor Agonist, in Rats, Monkeys and Mini-Pigs
}

\author{
Authors \\ Mitsuaki Takeuchi1,2, Masayuki Okamoto', Miyuki Tamura1, Takayo Murase' ${ }^{1}$, Nobuhide Watanabe ${ }^{1,2}$
}

\section{Affiliations}

1 Mie Research Laboratories, Sanwa Kagaku Kenkyusho Co., Ltd., Mie, Japan

2 Licensing \& Business Development, R\&D Strategy Center, Sanwa Kagaku Kenkyusho Co., Ltd., Tokyo, Japan

\section{Key words}

glucagon-like peptide- 1 receptor agonist, Type 2 diabetes, pharmacokinetics, tissue distribution

$\begin{array}{ll}\text { received } & 21.12 .2018 \\ \text { accepted } & 26.03 .2019\end{array}$

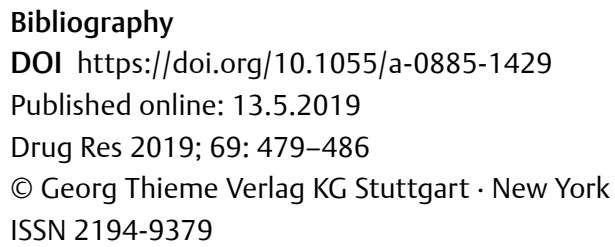

\section{Correspondence}

Mitsuaki Takeuchi

Licensing \& Business Development, R\&D Strategy Center

Sanwa Kagaku Kenkyusho Co., Ltd

Mitsui Building No.2 5F

1-1 Nihonbashi-Muromachi 2-Chome, Chuo-ku 103-0022 Tokyo

Japan

Tel.: + 81/3/6214 3006, Fax: + 81/3/32723023

m_takeuchi@mb4.skk-net.com

\begin{abstract}
Background Long-acting glucagon-like peptide- 1 receptor agonists (GLP-1 RAs) are widely used for treatment of type 2 diabetes (T2DM) in the United States, the European Union, and Japan. In our previous work, we designed and characterized a novel GLP-1 RA, SKL-18287. This RA consists of only natural L-amino acids, and is believed to exist in an oligomer form in systemic circulation. This unique feature may allow high biological stability and a long-lasting glucose lowering effect in T2DM treatment. In the present study, we investigated the pharmacokinetic properties of SKL-18287 in rats, monkeys, and mini-pigs. Tissue distributions of radioactivity were also studied in rats after subcutaneous administration of [ $\left.{ }^{3} \mathrm{H}\right]-S K L-18287$. Methods Plasma concentrations of SKL-18287 were measured by LC-MS/MS after intravenous and subcutaneous administration of SKL-18287 in rats, monkeys, and mini-pigs. Pharmacokinetic parameters were then calculated and compared among these animal species. Tissue concentrations of radioactivity were determined by liquid scintillation counting following sample combustion, after subcutaneous administration of $\left[{ }^{3} \mathrm{H}\right]$-SKL- 18287 to rats.

Results SKL-18287 showed an extended half-life of over $5 \mathrm{~h}$, with good subcutaneous bioavailability, in all animal species. Prediction of the pharmacokinetic profiles of SKL-18287 in humans using an animal scale-up approach revealed an SKL18287 half-life of $14.8 \mathrm{~h}$. The radioactivity concentration in the pancreas, a target tissue of GLP-1RA, was relatively higher than in other tissues, until $12 \mathrm{~h}$ after [ $\left.{ }^{3} \mathrm{H}\right]$-SKL-18287 administration. Conclusion SKL-18287 might be sufficient to maintain an effective concentration for a once-daily treatment for T2DM, and is a unique GLP-1 RA with a pancreas-selective feature.
\end{abstract}

\section{Introduction}

Glucagon-like peptide-1 (GLP-1) is an incretin hormone secreted from L-cells in the gastrointestinal tract in response to food intake $[1,2]$. GLP-1 regulates glucose homeostasis, stimulation of insulin release, and inhibition of glucagon secretion from pancreatic $\beta$-cells through GLP-1 receptor signals. Food intake and gastric emptying are also regulated through a GLP-1 receptor agonism effect [3-5]. GLP-1 has been shown to preserve or increase pancreatic $\beta$-cell mass through the inhibition of apoptosis, and stimulation of pro- liferation and differentiation. Therefore, GLP-1 receptor agonists (GLP-1 RAs) have the potential to improve diabetes and obesity. However, once GLP-1 is secreted into systemic circulation, it is rapidly degraded by dipeptidyl peptidase IV (DPP-4) and neutral endopeptidase 24.11 (NEP) [6, 7]. Consequently, the biological halflife of native GLP-1 is less than 2 min [8].

Recently, several synthetic GLP-1R agonists have been approved and made available for the treatment of type 2 diabetes (T2DM). 
These GLP-1 RAs are resistant to degradation by DPP-4 or NEP, and exhibit extended biological half-lives, a long-lasting glucose lowering effect, and a delay in the rate of gastric emptying [9-12]. Among these RAs, liraglutide has been well investigated for its pharmacological effects and pharmacokinetics in animal and clinical studies. The mechanism of biological stability of liraglutide was obtained from macromolecularization, with strong binding of albumin via acylated side chains [13]. The pharmacokinetic profiles of liraglutide revealed a long half-life and good subcutaneous bioavailability in humans [14]. Therefore, these features are suitable for once-daily administration.

In our previous studies, we designed and characterized a novel GLP-1 RA, SKL-18287. This RA consists of only natural L-amino acid, and is believed to exist in an oligomer form in systemic circulation, with a molecular weight of around 40,000 daltons [15]. This unique feature of self-association may result in high biological stability and a long-lasting glucose-lowering effect in T2DM treatment.

Interestingly, SKL-18287 shows a long-lasting glucose lowering effect in rodent diabetes models, and displays more potent therapeutic effects than liraglutide in a non-obese T2DM model (GotoKakizaki rats). SKL-18287 also displays a lower effect on gastric emptying in the early treatment period in normal rats [16].

The purpose of the present study is to characterize the pharmacokinetic profiles of SKL-18287 in various animal species, and to predict its biological half-life in humans. We also demonstrate the tissue distribution of radioactivity after administration of $\left[{ }^{3} \mathrm{H}\right]$ SKL-18287 in rats. These results might be useful for clinical study design for SKL-18287.

\section{Materials and Methods}

\section{Materials}

SKL-18287 (purity >95\%, > Fig. 1) and an internal standard (peptide 2, HAEGTFTSDVSSYLEGQAAKEFIAWLVKGKALIDEILAA-NH $\mathrm{N}_{2}$ ) were prepared by solid-phase peptide synthesis. Tritium-labeled SKL-18287 was synthesized by Sekisui Medical Co., Ltd (Tokyo, Japan) using tritium tyrosine, as described previously [15]. Formic acid, acetonitrile, $\mathrm{MeOH}$, toluene, $\mathrm{NH}_{4} \mathrm{OH}$, and EDTA-2K were purchased from Wako Pure Chemical Corporation (Osaka, Japan).

\section{Animals}

Seven-week old male Sprague-Dawley (SD) rats were purchased from Charles River Laboratories Japan, Inc. (Kanagawa, Japan). Eighteen- month old male cynomolgus monkeys were housed and studied at Japan Laboratory Animals, Inc. (Tokyo, Japan). Forty-month old mini-pigs were housed and studied at Nihon Bioresearch Center, Inc. (Gifu, Japan).

All animals were housed under standard conditions, with a 12-h light/dark cycle and free access to water and a commercial diet (CRF-1 for rats, PS-A for monkeys, and MP-A for mini-pigs; Oriental Yeast, Japan) for at least 5 days. All animal procedures were approved by the Sanwa Kagaku Kenkyusho Institutional Animal Care and Use Committee, and conducted in accordance with the institutional guidelines for the Conduct of Animal Experiments in Research Institutions under the Jurisdiction of the Ministry of Health, Labor, and Welfare (2006).

\section{Pharmacokinetic study in rats, monkeys, and mini-pigs}

SKL-18287 was suspended in phosphate-buffered saline (PBS) and administered intravenously or subcutaneously to male SD rats, male cynomolgus monkeys, and male mini-pigs. The doses for rats were $10 \mu \mathrm{g} / \mathrm{kg}$ for intravenous administration, and 10,30 , and $100 \mu \mathrm{g} / \mathrm{kg}$ for subcutaneous administration. The doses for monkeys and pigs were $17.4 \mu \mathrm{g} / \mathrm{kg}$ ( $4 \mathrm{nmol} / \mathrm{kg}$ ) for both administration routes. Blood samples were collected via the jugular vein for rats, the cephalic vein for monkeys, and the jugular venous or femoral venous catheter for mini-pigs, using a heparinized syringe at 0.083, 0.25, 0.5, 1, 2, 4, 6, $8,10,12,24,48$, and $72 \mathrm{~h}$ for intravenous and $0.25,0.5,1,2,4,6,8$, $10,12,24,48$, and $72 \mathrm{~h}$ for subcutaneous administration. Plasma was prepared by centrifugation $\left(1,500 \times \mathrm{g}, 4^{\circ} \mathrm{C}, 10 \mathrm{~min}\right)$ of the blood samples and stored at $-70{ }^{\circ} \mathrm{C}$ until analysis.

\section{Plasma sample preparation and LC-MS/MS conditions}

The plasma samples and peptide 2 were loaded onto an OASIS MCX 96-well plate that had been washed with $200 \mu \mathrm{L}$ of $\mathrm{MeOH}$ and equilibrated with $200 \mu \mathrm{L}$ of water. The wells were subsequently washed with $400 \mu \mathrm{L}$ of formic acid/water/acetonitrile $(1 / 95 / 5, \mathrm{v} / \mathrm{v} / \mathrm{v})$ and $400 \mu \mathrm{L}$ of acetonitrile. SKL-18287 and peptide 2 were eluted from the wells with $30 \mu \mathrm{L}$ of $28 \% \mathrm{NH}_{4} \mathrm{OH} /$ water/acetonitrile (5/50/50, $\mathrm{v} / \mathrm{v} / \mathrm{v})$, and the eluents were diluted with $70 \mu \mathrm{L}$ of formic acid/water/ acetonitrile $(5 / 50 / 50, v / v / v)$ for the analysis.

LC-MS/MS analyses were performed on an SC-10A HPLC system (Shimazu Corporation, Kyoto, Japan) coupled to an API 4000 tandem mass spectrometer (Sciex, Shimazu Corporation, Kyoto, Japan). Eluents were separated on the YMC Triart C8 $(2.0 \times 50 \mathrm{~mm}$, $5 \mu \mathrm{m}$, YMC Co., Ltd.) and kept at $50{ }^{\circ} \mathrm{C}$ using gradient flow of the

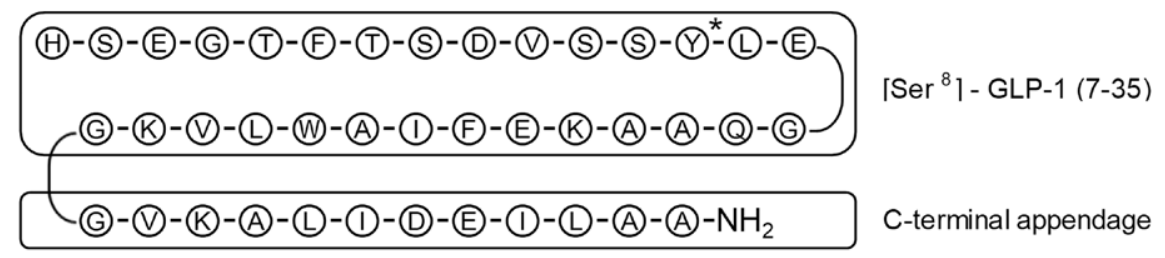

-Fig. 1 Primary structure of SKL-18287. * Position of the $\left[{ }^{3} \mathrm{H}\right]$ label. The C-terminal appendage is derived from the C-terminal helix 3 of the albumin binding domain 3 of protein G, from the bacterial Streptococcal G strain 148. Ref. [15]. 
mobile phase, consisting of buffer $A$ (formic acid/water $=0.5 / 100$, $\mathrm{v} / \mathrm{v}$ ) and buffer $B$ (formic acid/acetonitrile $=0.5 / 100, \mathrm{v} / \mathrm{v}$ ). SKL18287 was determined in the multiple reaction monitoring mode with positive ionization, using peptide 2 as an internal standard.

\section{Pharmacokinetic analysis}

The pharmacokinetic parameters were calculated using a non-compartmental analysis (WinNonlin Professional, Version 5.2.1; Pharsight Corporation, CA, USA). Bioavailability was calculated by dividing $\mathrm{AUC}_{0-\infty}$ after subcutaneous administration by $A U C_{0-\infty}$ after intravenous administration.

\section{Prediction of the human pharmacokinetic parameters of SKL-18287}

The allometric scaling method was used to predict the human pharmacokinetic parameters of SKL-18287 [17]. Body weight, plasma clearance, and volume of distribution after the intravenous administration of SKL-18287 were plotted between body weight and plasma clearance, and body weight and volume of distribution. The following equations were used for scaling of the plasma clearance and volume of distribution. The allometric coefficients ( $a, c)$ and allometric exponents (b, d) were calculated using data from the tested species.

$$
\begin{aligned}
& \text { CLp }(\mathrm{mL} / \mathrm{h})=\mathrm{a} \cdot \mathrm{W}^{\mathrm{b}} \\
& \text { Vdss }(\mathrm{mL})=\mathrm{c} \cdot \mathrm{W}^{\mathrm{d}} \\
& \text { W: body weight }(\mathrm{kg}) \\
& \text { a, c: allometric coefficients } \\
& \text { b, d: allometric exponents }
\end{aligned}
$$

Human plasma clearance and volume of distribution were estimated with the body weight set at $70 \mathrm{~kg}$. Elimination half-life was calculated by the following equation:

Predicted $\mathrm{t}_{1 / 2}=0.693 \cdot$ predicted human Vdss/Predicted human CLP

\section{Tissue distribution of radioactivity in rats}

Male SD rats ( $n=18 ; 3$ per time point) were administered a single subcutaneous dose of $30 \mu \mathrm{g}$ eq. $/ \mathrm{kg}$ of [ $\left.{ }^{3} \mathrm{H}\right]-\mathrm{SKL}-18287$ (414 MBq/mg), and the tissue concentration of radioactivity was determined at 0.5 , $2,6,12,24$, and $48 \mathrm{~h}$ after administration. At each time point, blood was collected using an EDTA-2K-containing syringe from the abdominal aorta, under anesthesia with isoflurane inhalation. Rats were sacrificed by exsanguination and the designated tissues were excised. Plasma was prepared by centrifugation $\left(1,500 \times \mathrm{g}, 4^{\circ} \mathrm{C}, 10 \mathrm{~min}\right)$ of the blood samples. Tissues collected from the SD rats were cerebrum, cerebellum, pituitary gland, spinal cord, eyeball, harderian gland, parotid gland, sublingual gland, mandibular gland, thyroid gland, trachea, mandibular lymph node, thymus, heart, lung, liver, kidney, adrenal gland, spleen, pancreas, aorta, fat, brown fat, skeletal muscle, dorsal skin, skin, thigh bone, bone marrow, testis, epididymis, seminal vesicle, prostate gland, urinary bladder, stomach, small intestine, cecum, and large intestine. Plasma and blood were each collected in a filter paper cup for combustion, as a sample for radioactivity assay. The other tissues were washed with saline, wiped with filter paper to remove saline, and weighed. The liver, pancreas, and kidney were each placed in a plastic container, mixed with the same volume of ice-cold acetonitrile, and minced. An equal weight of saline was then added, followed by homogenized with a polytron homogenizer. Approximate- ly $0.5 \mathrm{~g}$ (liver) and approximately $0.3 \mathrm{~g}$ (pancreas and kidney) aliquots of each prepared homogenate were collected in a filter paper cup. The entire dorsal skin, including the dosing site, was weighed, dissolved in $100 \mathrm{~mL}$ of a $2 \mathrm{~mol} / \mathrm{L}$ sodium hydroxide solution and $10 \mathrm{~mL}$ of toluene with heating, and diluted with water to $200 \mathrm{~mL}$. A $1 \mathrm{~mL}$ aliquot of the diluted solution was collected in a filter paper cup. The gastrointestinal tissues were weighed, dissolved in 10 (stomach, cecum, and large intestine) or 20 (small intestine) $\mathrm{mL}$ of $0.5 \mathrm{~mol} / \mathrm{L}$ sodium hydroxide solution with heating, and diluted with distilled water to 20 (stomach, cecum, and large intestine) or 40 (small intestine) $\mathrm{mL}$. A $1 \mathrm{~mL}$ aliquot of each diluted solution was collected in a filter paper cup. The gastrointestinal contents collected at washing of the gastrointestinal tract were placed in PP tubes previously rinsed with $1 \%$ Tween 80 and dried, for each region, mixed with distilled water to approximately $100 \mathrm{~g}$, and homogenized with a polytron homogenizer. An approximately $0.5 \mathrm{~g}$ aliquot of the homogenate was collected in a filter paper cup. The other tissues were collected entirely or in 150-mg aliquots of tissues in a filter paper cup. Each sample, in a filter paper cup for combustion, was dried at $40^{\circ} \mathrm{C}$ for more than $24 \mathrm{~h}$ in an incubator, and combusted using an automatic combustion system. Generated ${ }^{3} \mathrm{H}_{2} \mathrm{O}$ was absorbed in $12 \mathrm{~mL}$ of the scintillator Monophase S (PerkinElmer, USA), and subjected to the radioactivity assay. The measured values from the combustion method were corrected with the recovery, which was calculated using the ${ }^{3} \mathrm{H}$ standard sample (Spec-Chec- ${ }^{3} \mathrm{H}$, PerkinElmer, USA) for the sample oxidizer. The concentrations of radioactivity in blood, plasma, and tissues were measured by 2700 TR liquid scintillation counter (PerkinElmer, USA), and expressed as nmol eq./g or $\mathrm{mL}$.

\section{Results}

\section{Pharmacokinetics study in rats}

The plasma concentration time profiles of SKL-18287 in male SD rats after intravenous $(10 \mu \mathrm{g} / \mathrm{kg})$ and subcutaneous administration $(10,30$, and $100 \mu \mathrm{g} / \mathrm{kg})$ are shown in $>$ Fig. 2. The PK parameters of SKL-18287 in rats are shown in > Table 1. For intravenous administration, SKL-18287 was disposed in a biphasic manner, and the elimination half-life was $5.4 \pm 0.3 \mathrm{~h}$. The plasma clearance (CLp) and apparent volume of distribution (Vdss) were $11.8 \pm 0.3 \mathrm{~mL} / \mathrm{h} /$ $\mathrm{kg}$ and $75.6 \pm 1.7 \mathrm{~mL} / \mathrm{kg}$, respectively. The area under the plasma concentration curve (AUC) of SKL-18287 was $851 \pm 23 \mathrm{ng} \cdot \mathrm{h} / \mathrm{mL}$. For subcutaneous administration, AUC and Cmax revealed a dose-dependent increase $(10-100 \mu \mathrm{g} / \mathrm{kg})$. The mean Tmax and bioavailability (BA) were from 3.2 to $4.0 \mathrm{~h}$, and 64.3 to $68.4 \%$, respectively. The mean elimination half-life ( 5.2 to $5.8 \mathrm{~h}$ ) and mean MRT (8.8$9.7 \mathrm{~h}$ ) changed little among the 3 dose groups.

\section{Pharmacokinetics study in monkeys and mini-pigs}

The plasma concentration time profiles of SKL-18287 in cynomolgus monkeys and mini-pigs after intravenous and subcutaneous administration $(17.4 \mu / \mathrm{kg})$ are shown in $\triangleright \mathbf{F i g}$. 3. The pharmacokinetic parameters of SKL-18287 in monkeys and pigs are summarized in $>$ Table 2. For intravenous administration, SKL-18287 was disposed in a biphasic manner in monkeys. A bimodal distribution was observed in mini-pigs. The elimination half-life for monkeys and pigs was $9.0 \pm 1.8 \mathrm{~h}$ and $12.9 \pm 1.0 \mathrm{~h}$, respectively. The CLp and Vdss were similarly low for both species, at $2.89 \mathrm{~mL} / \mathrm{h} / \mathrm{kg}$ and 
$34.0 \mathrm{~mL} / \mathrm{kg}$, respectively for monkeys, and $3.68 \mathrm{~mL} / \mathrm{h} / \mathrm{kg}$ and $67.0 \mathrm{~mL} / \mathrm{kg}$, respectively for pigs. For subcutaneous administration, AUC and Cmax were similar for both species at $3800 \pm 1310 \mathrm{ng} \cdot \mathrm{h} /$ $\mathrm{mL}$ and $151 \pm 37.2 \mathrm{ng} / \mathrm{mL}$, respectively for monkeys, and $3960 \pm$ $943 \mathrm{ng} \cdot \mathrm{h} / \mathrm{L}$ and $130 \pm 30 \mathrm{ng} \cdot \mathrm{h} / \mathrm{mL}$, respectively for pigs. The tmax was $6.7 \mathrm{~h}$ for monkeys and $8.7 \mathrm{~h}$ for pigs. The mean bioavailability was $58.1 \%$ for monkeys and $87.6 \%$ for mini-pigs.

\section{Prediction of human pharmacokinetic parameters}

The interspecies relationships for the clearance and volume of distribution taken from all animal data are shown in > Fig. 4. All data were fitted using allometric equations, and allometric coefficients were calculated. A good correlation was observed between body weight and clearance, and between body weight and volume of distribution. The clearance and volume of distribution of SKL-18287 in humans were then predicted using allometric equations. The calculated parameters in humans are shown in > Table 3. When the human weight was set at $70 \mathrm{~kg}$, the plasma clearance and volume

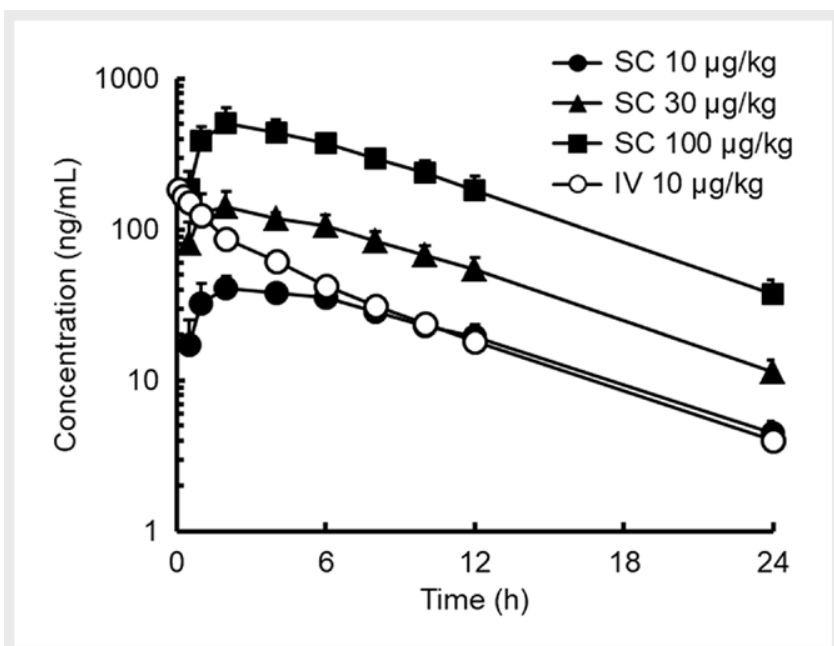

Fig. 2 Plasma concentration vs. the time profile of SKL-18287 in male SD rats, after single intravenous (IV) and subcutaneous (SC) administration of SKL-18287 at a doses of 10 and 10 to $100 \mu \mathrm{g} / \mathrm{kg}$, respectively. Data are expressed as mean $\pm \operatorname{SD}(n=5)$. of distribution were calculated at $148 \mathrm{~mL} / \mathrm{h}$ and $3170 \mathrm{~mL}$, respectively. The estimated half-life in humans was $14.8 \mathrm{~h}$.

\section{Tissue distribution of radioactivity in rats}

Following a single subcutaneous administration of $30 \mu \mathrm{g}$ eq. $/ \mathrm{kg}$ of $\left[{ }^{3} \mathrm{H}\right]-\mathrm{SKL}-18287$ to rats, radioactivity was highest in most tissues at $6 \mathrm{~h}$ post-dose ( $\vee$ Table 4 ), indicating relatively slow distribution to tissues. The radioactivity in tissues at $6 \mathrm{~h}$ after dosing was highest in plasma, followed by pancreas, blood, adrenal grand, bone marrow, and liver. Low radioactivity levels were found in the fat, cerebrum, cerebellum, and spinal cord during the study period. The tissue concentration vs. the time profiles of radioactivity and tissue to plasma concentration ratios after administration of $\left[{ }^{3} \mathrm{H}\right]$ SKL-18287 is shown in $\mathbf{F i g}$. $\mathbf{5}$. The radioactivity concentrations of pancreas and liver were relatively higher than those of other tissues until $12 \mathrm{~h}$ post dose, and disappeared as the plasma concentration decreased. The tissue concentrations of radioactivity in heart, kidney, and lung showed relatively slow absorption and disappearance, compared to plasma. The tissue concentrations of radioactivity in cerebrum, cerebellum, thyroid gland, stomach, small intestine, and large intestine showed slow absorption, and then reached a steady state after $24 \mathrm{~h}$ post-dose.

\section{Discussion}

In this present study, we investigated the pharmacokinetic properties of SKL-18287, a novel long acting GLP-1 RA, in rats, monkeys, and mini-pigs. After intravenous administration of SKL-18287, the apparent volume of distribution was similar to the plasma volume, in all animal species. These results indicate that a large fraction of SKL-18287 is localized to systemic circulation. After subcutaneous administration, SKL-18287 was slowly absorbed into systemic circulation, reaching a maximum concentration at around 3.2 to $4 \mathrm{~h}$ in rats, and 6.7 and $8.7 \mathrm{~h}$ in monkeys and mini-pigs, respectively. The elimination half-life after intravenous and subcutaneous administration of SKL-18287 was shorter in rats (IV, $5.4 \mathrm{~h}$; SC, 5.2 to $5.8 \mathrm{~h}$ ) than in monkeys (IV, $9.0 \mathrm{~h}$; SC, $11.4 \mathrm{~h}$ ) and in mini-pigs (IV, 12.9 h; SC, $15.4 \mathrm{~h}$ ). Since SKL-18287 is highly stable in rat and human plasma [15], the elimination rate of SKL-18287 from systemic circulation may depend on the order of the plasma flow rate in the kidneys [18]. SKL-18287 exhibited good bioavailability in all animal species, indi-

- Table 1 Pharmacokinetic parameters of SKL-18287 administered to male SD rats.

\begin{tabular}{|c|c|c|c|c|}
\hline \multirow[t]{2}{*}{ Parameters } & \multirow{2}{*}{$\frac{\mathrm{IV}}{10 \mu \mathrm{g} / \mathrm{kg}}$} & \multicolumn{3}{|l|}{ SC } \\
\hline & & $10 \mu \mathrm{g} / \mathrm{kg}$ & $30 \mu \mathrm{g} / \mathrm{kg}$ & $100 \mu \mathrm{g} / \mathrm{kg}$ \\
\hline Cmax (ng/mL) & - & $43.0 \pm 5.4$ & $145 \pm 34$ & $507 \pm 132$ \\
\hline$T \max (\mathrm{h})$ & - & $4.0 \pm 2.0$ & $3.2 \pm 1.8$ & $3.2 \pm 1.8$ \\
\hline $\mathrm{AUC}_{0-\mathrm{t}}(\mathrm{ng} \cdot \mathrm{h} / \mathrm{mL})$ & $820 \pm 19$ & $510 \pm 58$ & $1560 \pm 140$ & $5810 \pm 920$ \\
\hline$A \cup C_{0-\infty}(\mathrm{ng} \cdot \mathrm{h} / \mathrm{mL})$ & $851 \pm 23$ & $548 \pm 66$ & $1640 \pm 150$ & $5820 \pm 930$ \\
\hline $\mathrm{CLp}(\mathrm{mL} / \mathrm{h} / \mathrm{kg})$ & $11.8 \pm 0.3$ & - & - & - \\
\hline$V \mathrm{dss}(\mathrm{mL} / \mathrm{kg})$ & $75.6 \pm 1.7$ & - & - & - \\
\hline$t 1 / 2(\mathrm{~h})$ & $5.4 \pm 0.3$ & $5.8 \pm 0.4$ & $5.4 \pm 0.3$ & $5.2 \pm 0.2$ \\
\hline MRT (h) & $6.4 \pm 0.2$ & $9.7 \pm 0.7$ & $8.8 \pm 1.0$ & $9.0 \pm 0.1$ \\
\hline BA (\%) & - & $64.3 \pm 7.7$ & $64.4 \pm 5.7$ & $68.4 \pm 10.9$ \\
\hline
\end{tabular}



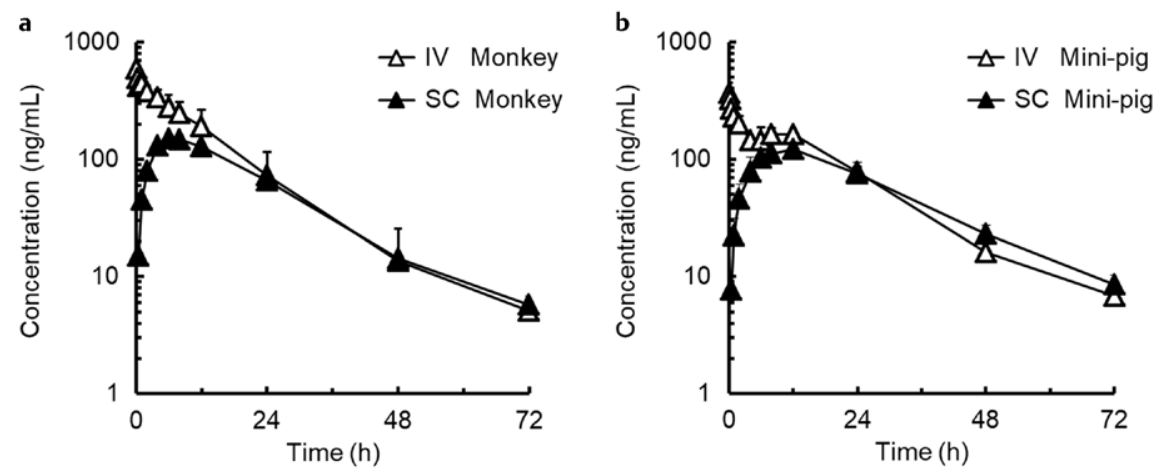

- Fig. 3 Plasma concentrations vs. the time profile of SKL-18287 in monkeys and mini-pigs, after single intravenous (IV) and subcutaneous (SC) administration of SKL-18287 at a dose of $17.4 \mu \mathrm{g} / \mathrm{kg}$ : a monkeys, $\mathbf{b}$ mini-pigs. Data are expressed as mean \pm SD $(n=3-5)$.

D Table 2 Pharmacokinetic parameters of SKL-18287 administered to monkeys and mini-pigs.

\begin{tabular}{|l|l|l|l|c|}
\hline parameters & Monkey & Mini-pig \\
\hline Route & $\mathrm{IV}$ & $\mathrm{SC}$ & $\mathrm{IV}$ & $\mathrm{SC}$ \\
\hline $\mathrm{Cmax}(\mathrm{ng} / \mathrm{mL})$ & - & $151 \pm 37.2$ & - & $130 \pm 30$ \\
\hline $\max (\mathrm{h})$ & - & $6.7 \pm 1.2$ & - & $8.7 \pm 3.1$ \\
\hline $\mathrm{AUC}_{0-\mathrm{t}}(\mathrm{ng} \cdot \mathrm{h} / \mathrm{mL})$ & $6350 \pm 2330$ & $3660 \pm 1360$ & $4960 \pm 477$ & $3770 \pm 912$ \\
\hline $\mathrm{AUC}_{0-\infty}(\mathrm{ng} \cdot \mathrm{h} / \mathrm{mL})$ & $6400 \pm 2340$ & $3800 \pm 1310$ & $5090 \pm 519$ & $3960 \pm 943$ \\
\hline $\mathrm{CLp}(\mathrm{mL} / \mathrm{h} / \mathrm{kg})$ & $2.89 \pm 0.89$ & - & $3.68 \pm 0.36$ & - \\
\hline $\mathrm{Vdss}(\mathrm{mL} / \mathrm{kg})$ & $34.0 \pm 4.6$ & - & $67.0 \pm 4.3$ & - \\
\hline$t_{1 / 2}(\mathrm{~h})$ & $9.0 \pm 1.8$ & $11.4 \pm 1.0$ & $12.9 \pm 1.0$ & $15.4 \pm 0.3$ \\
\hline $\mathrm{MRT}(\mathrm{h})$ & $12.3 \pm 2.6$ & $18.6 \pm 1.5$ & $18.2 \pm 0.7$ & $25.5 \pm 0.7$ \\
\hline BA $(\%)$ & - & $58.1 \pm 20.0$ & - & $87.6 \pm 13.6$ \\
\hline Data are expressed as the mean $\pm \mathrm{SD}(\mathrm{n}=3)$. IV; intravenous administration, SC; subcutaneous administration, BA; bioavailability \\
\hline
\end{tabular}
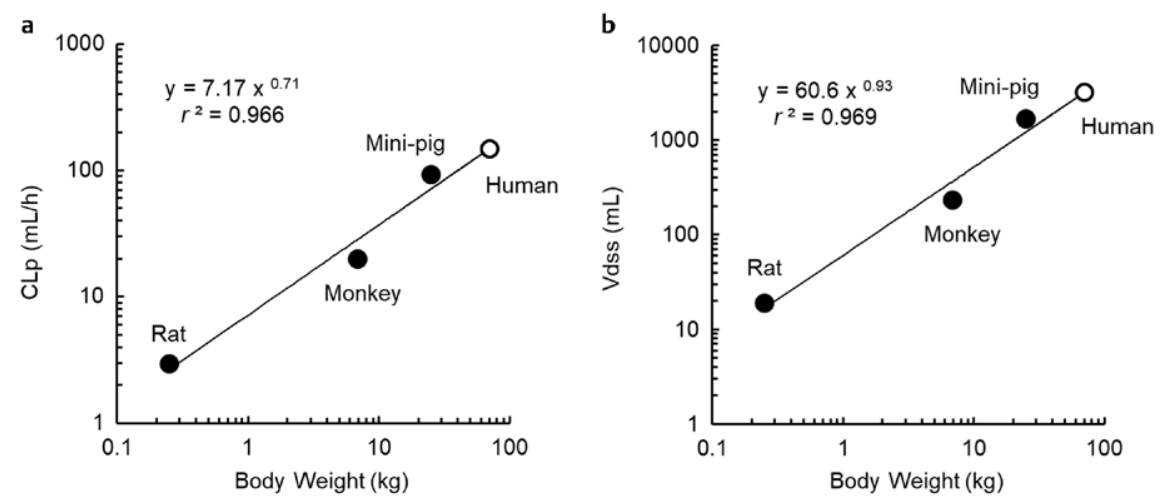

- Fig. 4 Allometric relationships between body weight and a plasma clearance and $\mathbf{b}$ volume of distribution of SKL-18287. The linear regression for the logarithmic values was calculated using the least-squares method ( $\left.a: y=7.17 \times 0.71, r^{2}=0.966 ; b: y=60.6 \times 0.93, r^{2}=0.969\right)$. Extrapolated human values, based on a body weight of $70 \mathrm{~kg}$ (open circles) and values from individual animals (black circles) are also shown.

cating the SKL-18287 was almost fully absorbed from the subcutaneous tissues. Based on the studies of Steensgaard, et al. [19] and Wang, et al. [20], liraglutide forms an oligomer (heptamer, octamer, or dodecamer) in solution, a feature considered to result in slow absorption from the dosing site (subcutaneous tissue). SKL-18287 also forms an oligomer in solution, and similar phenomena (i. e., slow absorption) were observed in all animal species.

A number of studies on protein and peptide drugs have shown that allometric scaling is effective in predicting human clearance and volume of distribution [21-23]. The relationship between plas- 
- Table 3 Predicted human pharmacokinetic parameters for SKL-18287.

\begin{tabular}{|l|c|c|c|c|}
\hline & $\mathbf{W} \mathbf{( k g )}$ & $\boldsymbol{C L} \mathbf{p}(\mathbf{m L} / \mathbf{h})$ & $\boldsymbol{V d s s}(\mathbf{m L})$ & $\boldsymbol{t}_{1 / 2}(\mathbf{h})$ \\
\hline Rat & 0.25 & 2.95 & 18.9 & 4.44 \\
\hline Monkey & 6.9 & 19.8 & 233 & 8.2 \\
\hline Mini-pig & 25.0 & 92 & 1675 & 12.6 \\
\hline Human & 70.0 & 148 & 3170 & 14.8 \\
\hline
\end{tabular}

ma clearance and body weight, and between volume of distribution and body weight revealed high correlations, and human pharmacokinetic parameters were predicted by a simple allometric scaling equation [17]. The estimated half-life of SKL-18287 in humans was $14.8 \mathrm{~h}$, a result that was similar to those of liraglutide in healthy volunteers (range 11-15 h) [14].

- Table 4 Concentrations of the radioactivity in the tissues of SD rats after a single subcutaneous administration of [ $\left.{ }^{3} \mathrm{H}\right]-\mathrm{SKL}-18287$, at a dose of $30 \mu \mathrm{g}$ eq. $/ \mathrm{kg}$.

\begin{tabular}{|c|c|c|c|c|c|c|}
\hline \multirow[t]{2}{*}{ Tissue } & \multicolumn{6}{|c|}{ Radioactivity concentration (ng eq. of SKL-18287/g or mL) } \\
\hline & $0.5 \mathrm{~h}$ & $2 \mathrm{~h}$ & 6h & $12 \mathrm{~h}$ & $24 \mathrm{~h}$ & $48 \mathrm{~h}$ \\
\hline Plasma & $98 \pm 14.2$ & $214 \pm 36$ & $191 \pm 1$ & $85.9 \pm 14.4$ & $29.5 \pm 4.9$ & $12.6 \pm 0.5$ \\
\hline Blood & $59.4 \pm 7.3$ & $133 \pm 20$ & $115 \pm 3$ & $54.9 \pm 9.1$ & $22 \pm 3.1$ & $13.4 \pm 0.3$ \\
\hline Cerebrum & $1.79 \pm 0.49$ & $4.73 \pm 0.13$ & $7.05 \pm 0.04$ & $8.24 \pm 0.28$ & $7.86 \pm 0.18$ & $8.27 \pm 0.27$ \\
\hline Cerebellum & $2.06 \pm 0.89$ & $5.19 \pm 0.05$ & $7.81 \pm 0.06$ & $8.67 \pm 0.54$ & $8.15 \pm 0.39$ & $8.66 \pm 0.28$ \\
\hline Pituitary gland & $12.2 \pm 4.4$ & $31.3 \pm 4.6$ & $41.7 \pm 8.8$ & $52.7 \pm 3.7$ & $38 \pm 4.8$ & $26.9 \pm 0.3$ \\
\hline Spinal cord & $2.01 \pm 0.93$ & $3.6 \pm 0.25$ & $6.44 \pm 0.78$ & $6.58 \pm 0.12$ & $5.81 \pm 0.39$ & $5.98 \pm 0.15$ \\
\hline Eyeball & $1.43 \pm 0.42$ & $4.97 \pm 0.33$ & $8.08 \pm 0.83$ & $7.75 \pm 0.23$ & $7.05 \pm 0.03$ & $6.8 \pm 0.29$ \\
\hline Harderian gland & $3.65 \pm 0.87$ & $11.4 \pm 1.2$ & $20.4 \pm 0.5$ & $29.1 \pm 0.8$ & $25.1 \pm 1.5$ & $23.8 \pm 1.1$ \\
\hline Parotid gland & $7.81 \pm 1.45$ & $35.1 \pm 1.5$ & $70 \pm 9.7$ & $54.2 \pm 12.6$ & $31.4 \pm 6.2$ & $20.6 \pm 2.6$ \\
\hline Sublingual gland & $7.06 \pm 1.45$ & $29 \pm 4.2$ & $43.6 \pm 2.6$ & $34.7 \pm 3.3$ & $25.5 \pm 3$ & $19.5 \pm 0.8$ \\
\hline Mandibular gland & $7.81 \pm 2.25$ & $29.8 \pm 4.1$ & $49.7 \pm 5.6$ & $39.9 \pm 1.7$ & $26.1 \pm 3.1$ & $22.8 \pm 1.2$ \\
\hline Thyroid gland & $13.4 \pm 4.2$ & $30.1 \pm 7.3$ & $38.9 \pm 8.2$ & $40.8 \pm 1.3$ & $24.2 \pm 4.6$ & $24 \pm 4.5$ \\
\hline Trachea & $4.66 \pm 0.93$ & $11.2 \pm 5$ & $26.9 \pm 8.1$ & $20.9 \pm 3.4$ & $16.4 \pm 5.6$ & $13.4 \pm 0.8$ \\
\hline Mandibular lymph node & $4.73 \pm 0.86$ & $22.3 \pm 1.6$ & $33.8 \pm 4.9$ & $36.3 \pm 0.8$ & $26.1 \pm 3.4$ & $25.9 \pm 1.6$ \\
\hline Thymus & $3.31 \pm 1.41$ & $12.3 \pm 1$ & $23.6 \pm 1.7$ & $31.2 \pm 2.1$ & $31.2 \pm 2.6$ & $29.7 \pm 0.1$ \\
\hline Heart & $7.92 \pm 1.75$ & $21.8 \pm 2.4$ & $29.5 \pm 0.3$ & $23.2 \pm 1.3$ & $18.7 \pm 0.6$ & $17 \pm 0.1$ \\
\hline Lung & $11.1 \pm 1.1$ & $31 \pm 2.6$ & $58.7 \pm 1.9$ & $64.3 \pm 6$ & $64.6 \pm 12.3$ & $53.8 \pm 11.9$ \\
\hline Liver & $25.2 \pm 6.3$ & $93.6 \pm 28.4$ & $78.9 \pm 3.8$ & $69.6 \pm 7.2$ & $35.7 \pm 1.9$ & $26 \pm 0.4$ \\
\hline Kidney & $23 \pm 3.7$ & $55.7 \pm 4.9$ & $54.6 \pm 5.4$ & $55.7 \pm 1.4$ & $42.8 \pm 0.7$ & $34.7 \pm 0.3$ \\
\hline Adrenal gland & $32.8 \pm 7.2$ & $76.9 \pm 16.6$ & $90.9 \pm 19.7$ & $66.3 \pm 6.8$ & $44.9 \pm 6.1$ & $31.2 \pm 3.3$ \\
\hline Spleen & $8.59 \pm 1.64$ & $31.6 \pm 7.3$ & $42.4 \pm 2$ & $48.5 \pm 3.7$ & $42 \pm 5.2$ & $29.8 \pm 2.4$ \\
\hline Pancreas & $20.1 \pm 6.6$ & $93.5 \pm 14.3$ & $132 \pm 8$ & $96.4 \pm 21.3$ & $36.6 \pm 2.7$ & $22.5 \pm 1.5$ \\
\hline Aorta & $4.49 \pm 1.06$ & $12.4 \pm 0.7$ & $21.7 \pm 7.8$ & $21.6 \pm 3.2$ & $17.9 \pm 5.2$ & $15.3 \pm 3.3$ \\
\hline Fat & $0.935 \pm 0.2$ & $2.71 \pm 0.28$ & $3.27 \pm 0.65$ & $3.28 \pm 0.48$ & $3.99 \pm 0.22$ & $3.46 \pm 0.27$ \\
\hline Brown fat & $4.42 \pm 1.35$ & $11.2 \pm 1$ & $26.1 \pm 6.6$ & $19.6 \pm 0.8$ & $16.7 \pm 3.3$ & $19.2 \pm 2.6$ \\
\hline Skeletal muscle & $2.09 \pm 0.43$ & $7.07 \pm 0.97$ & $11.9 \pm 0.5$ & $11.3 \pm 1.3$ & $13.3 \pm 0.5$ & $12.4 \pm 1.7$ \\
\hline Dorsal skin * & $382 \pm 64$ & $130 \pm 36$ & $51.8 \pm 19.4$ & $37 \pm 4.3$ & $26.4 \pm 1.8$ & $22.2 \pm 5.4$ \\
\hline Skin & $3.77 \pm 0.71$ & $16.8 \pm 0.7$ & $28.7 \pm 2.3$ & $30.9 \pm 3.7$ & $38.5 \pm 5.4$ & $30.1 \pm 5.3$ \\
\hline Thigh bone & $5.37 \pm 1.1$ & $15.3 \pm 5.2$ & $20.4 \pm 4.5$ & $14.1 \pm 4.3$ & $12.5 \pm 3.8$ & $10.4 \pm 1.4$ \\
\hline Bone marrow & $10.5 \pm 1.6$ & $51.2 \pm 16.3$ & $79.3 \pm 15.4$ & $108 \pm 13$ & $96.3 \pm 15.3$ & $64.7 \pm 7.7$ \\
\hline Testis & $1.92 \pm 0.28$ & $10.6 \pm 2.3$ & $20.2 \pm 4.4$ & $17.7 \pm 1.1$ & $15.5 \pm 1.6$ & $12.6 \pm 0.6$ \\
\hline Epididymis & $2.3 \pm 0.63$ & $10.4 \pm 2.1$ & $20.6 \pm 0.8$ & $22.1 \pm 1.4$ & $17.9 \pm 1.1$ & $14.9 \pm 1.4$ \\
\hline Seminal vesicle & $4.66 \pm 1.59$ & $14.8 \pm 0.8$ & $34.1 \pm 1.2$ & $39.2 \pm 4$ & $37.5 \pm 1.7$ & $42.4 \pm 8.5$ \\
\hline Prostate gland & $5.67 \pm 1.62$ & $26.8 \pm 9.4$ & $39.9 \pm 9$ & $47.1 \pm 5.5$ & $41.9 \pm 3.8$ & $34.9 \pm 4$ \\
\hline Urinary bladder & $3.93 \pm 0.64$ & $15.8 \pm 4.2$ & $27.3 \pm 2.2$ & $23.7 \pm 1.7$ & $16.2 \pm 0.6$ & $14.5 \pm 1.7$ \\
\hline Stomach & $6.35 \pm 1.33$ & $23.4 \pm 3.7$ & $43.2 \pm 5.2$ & $44.8 \pm 2.5$ & $28.8 \pm 5.6$ & $23.9 \pm 3.2$ \\
\hline Small intestine & $5.64 \pm 0.59$ & $21.8 \pm 4.9$ & $37.2 \pm 3.5$ & $48.9 \pm 6.5$ & $37.8 \pm 3.7$ & $23.2 \pm 4.5$ \\
\hline Cecum & $5.13 \pm 0.66$ & $17.4 \pm 4$ & $30.3 \pm 2.9$ & $40.9 \pm 15.2$ & $26.4 \pm 2.8$ & $22.9 \pm 0.7$ \\
\hline Large intestine & $4.26 \pm 0.54$ & $13.9 \pm 3.6$ & $23.2 \pm 3.2$ & $24.9 \pm 1.4$ & $22.5 \pm 0.8$ & $18.9 \pm 1.4$ \\
\hline
\end{tabular}




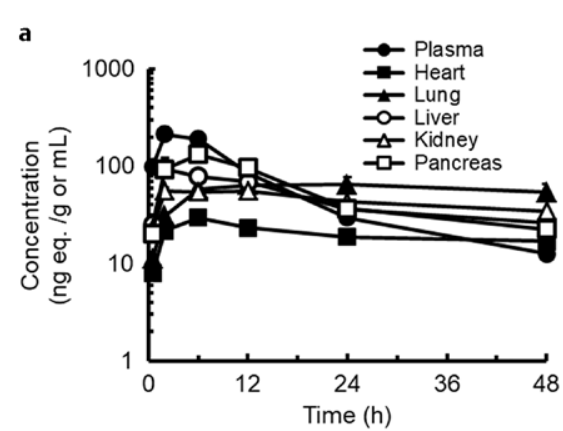

$c$

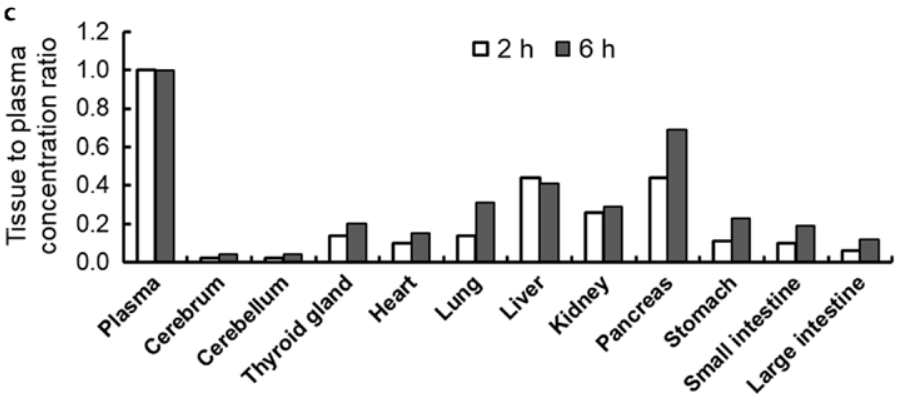

b $1000 \quad \rightarrow$ Plasma

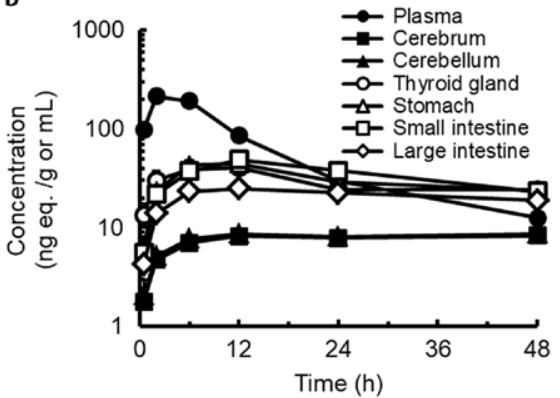

I- Cerebellum

- Stomach

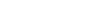

\section{.


[6] Mentlein R, Gallwitz B, Schmidt WE. Dipeptidyl-peptidase IV hydrolyses gastric inhibitory polypeptide, glucagon-like peptide-1(7-36)amide, peptide histidine methionine and is responsible for their degradation in human serum. Eur J Biochem 1993; 214: 829-835

[7] Plamboeck A, Holst J], Carr RD et al. Neutral endopeptidase 24.11 and dipeptidyl peptidase IV are both mediators of the degradation of glucagon-like peptide 1 in the anaesthetised pig. Diabetologia 2005; 48: $1882-1890$

[8] Deacon CF, Pridal L, Klarskov L et al. Glucagon-like peptide 1 undergoes differential tissue-specific metabolism in the anesthetized pig. Am J Physiol 1996; 271: E458-E464

[9] Eng J, Kleinman WA, Singh L et al. Isolation and characterization of exendin-4, an exendin-3 analogue, from Heloderma suspectum venom. Further evidence for an exendin receptor on dispersed acini from guinea pig pancreas. J Biol Chem 1992; 267: 7402-7405

[10] Chen YE, Drucker DJ. Tissue-specific expression of unique mRNAs that encode proglucagon-derived peptides or exendin 4 in the lizard. J Biol Chem 1997; 272: 4108-4115

[11] Courtney H, Nayar R, Rajeswaran C et al. Long-term management of type 2 diabetes with glucagon-like peptide- 1 receptor agonists. Diabetes Metab Syndr Obes 2017; 10: 79-87

[12] Thompson AM, Trujillo JM. Dulaglutide: The newest GLP-1 receptor agonist for the management of type 2 diabetes. Ann Pharmacother 2015; 49: 351-359

[13] Plum A, Jensen LB, Kristensen JB. In vitro protein binding of liraglutide in human plasma determined by reiterated stepwise equilibrium dialysis. J Pharm Sci 2013; 102: 2882-2888

[14] Elbrønd B, Jakobsen G, Larsen S et al. Pharmacokinetics, pharmacodynamics, safety, and tolerability of a single-dose of NN2211, a long-acting glucagon-like peptide 1 derivative, in healthy male subjects. Diabetes Care 2002; 25: 1398-1404
[15] Takeuchi M, Okamoto M, Okamoto R et al. Discovery of a long-acting glucagon-like peptide-1 analog with enhanced aggregation propensity. Peptides 2018; 102: 8-15

[16] Takeuchi M, Okamoto M, Watanabe N. Pharmacological evaluation of SKL-18287, a new long-acting glucagon-like peptide receptor agonist with enhanced aggregation propensity, in rodent models. Int J Pept Res Ther 2018, doi:https://doi.org/10.1007/s10989-018-9777-7

[17] Boxenbaum H. Interspecies pharmacokinetic scaling and the evolutionary-comparative paradigm. Drug Metab Rev 1984; 15 : $1071-1121$

[18] Gerlowski LE, Jain RK. Physiologically based pharmacokinetic modeling: principles and applications. J Pharm Sci 1983; 72: 1103-1127

[19] Steensgaard D, Thomsen J, Knudsen L et al. The molecular basis for the delayed absorption of the once-daily human GLP-1 analog , liraglutide. Diabetes 2008; 57: A164

[20] Wang Y, Lomakin A, Kanai S et al. Transformation of oligomers of lipidated peptide induced by change in $\mathrm{pH}$. Mol Pharm 2015; 12: 411-419

[21] Wang W, Prueksaritanont T. Prediction of human clearance of therapeutic proteins: Simple allometric scaling method revisited. Biopharm Drug Dispos 2010; 31: 253-263

[22] Mordenti J, Chen SA, Moore JA et al. Interspecies scaling of clearance and volume of distribution data for five therapeutic proteins. Pharm Res 1991; 8: 1351-1359

[23] Mahmood I. Interspecies scaling of protein drugs: Prediction of clearance from animals to humans. J Pharm Sci 2004; 93: 177-185 